\title{
Effect of insulin and transferrin in the maintenance of the activated state of the T-lymphocyte induced by allo-antigen
}

\author{
J.H. Helderman, R. Gruchalla and L. E. Edwards \\ University of Texas Health Science Center at Dallas, Dallas, Texas, USA
}

Summary. Insulin is an immuno-modulating molecule enhancing cytotoxic T-cell function and supporting intermediary metabolism in activated lymphocytes. Insulin also maintains the activated state of mitogen-stimulated lymphocytes. Because of the importance of allo-antigen response of diabetic patients for infections and transplant immunity, we explored the role of insulin in the allo-activated state of lymphocytes. Allo-stimulation was provided in one-way mixed lymphocyte reactions, with Balb/C mouse lymph node cells responding to irradiated spleen cells of $\mathrm{C} 57 \mathrm{BL} / 6$ mice, in culture under conditions which permitted evaluation of hormonal modulation. Mixed lymphocyte reactions established in fetal calf serum, insulin-depleted by passage over antibody affinity columns, were of equal magnitude to those in insulin-replete serum. A weak but positive mixed lymphocyte reaction can be effected with an artificial serum substitute containing no additional hormone. Provision of insulin $(10 \mathrm{nmol} / \mathrm{l})$ restored a full mixed lymphocyte reaction response which was mimicked by addition of transferrin. The insulin-transferrin combination was not additive. In conclusion, insulin and transferrin maintain the allo-activated state of the mouse lymphocyte, transferrin alone being sufficient when full antigenic stimulation is provided. If the same applies to human lymphocytes, insulin-deficient diabetic patients will respond to full allo-antigen challenge, and so should be fully capable of mounting a transplant immune response.

Key words: Transferrin, insulin, T-lymphocyte, allo-antigen mouse.
Insulin is an immuno-modulating molecule. When provided to lymphocytes induced to synthesize a complement of insulin receptors by antigen stimulation, insulin subserves several biological functions $[1,2]$. It can enhance the cytotoxic function of killer T-cells while supporting increased energy demands of activated cells through intermediary metabolism $[1,2]$. Recently it has been shown in a submaximal mitogen model that insulin will support and maintain the active state of lymphocytes which would otherwise have returned to a quiescent state after completing one cell-cycle [3]. Allo-response is essential for immune surveillance against neoplasia and virally infected self, as well as for transplant immunity. Since Type 1 (insulin-dependent) diabetic patients are insulin deficient and receive treatment which generally permits wide swings in plasma insulin, it is crucial that the role of insulin in the maintenance of the lymphocyte allo-response is understood. Towards just such an understanding these studies have been directed.

\section{Materials and methods}

\section{Cell preparation}

Lymph nodes and spleens extracted from $\mathrm{Balb} / \mathrm{C}\left(\mathrm{H}-2^{\mathrm{d}}\right)$ and from $\mathrm{C} 57 \mathrm{BL} / 6\left(\mathrm{H}-2^{b}\right)$ mice were ground individually through a wire grid into RPMI-1640 medium buffered with HEPES $(10 \mathrm{mmol} / \mathrm{l})$. Mononuclear cells were obtained from the cell suspensions by passage over a Ficoll-Hypaque density gradient. One-way mixed lymphocyte reactions were established by culturing $8 \times 10^{6}$ lymph node cells of the responder strain with $8 \times 10^{6}$ spleen cells of the stimulator strain previously irradiated for $20 \mathrm{~min}$ by a caesium source. Cultures proceeded for 5 days in RPMI-1640 medium, with HEPES $(10 \mathrm{mmol} / 1)$ and the test growth factor in 12-well cluster plates (Costar Plastics, Cambridge, Massachusetts, USA). Cells were harvested and then placed into 96-well microtitre plates at $0.5 \times 10^{6}$ cells/well in $100 \mu 1$ of medium to which was added $1 \mu \mathrm{Ci}{ }^{3} \mathrm{H}$-thymidine. Culture continued for $16 \mathrm{~h}$ before harvest over glass fibre filters by a Mash 11 harvester (Microbiology Associates, Bethesda, Maryland, USA).

\section{Insulin-depleted serum}

The role of insulin was first tested by effecting the mixed lymphocyte reaction in $1 \%$ fetal-calf-serum-enriched medium or in serum which 


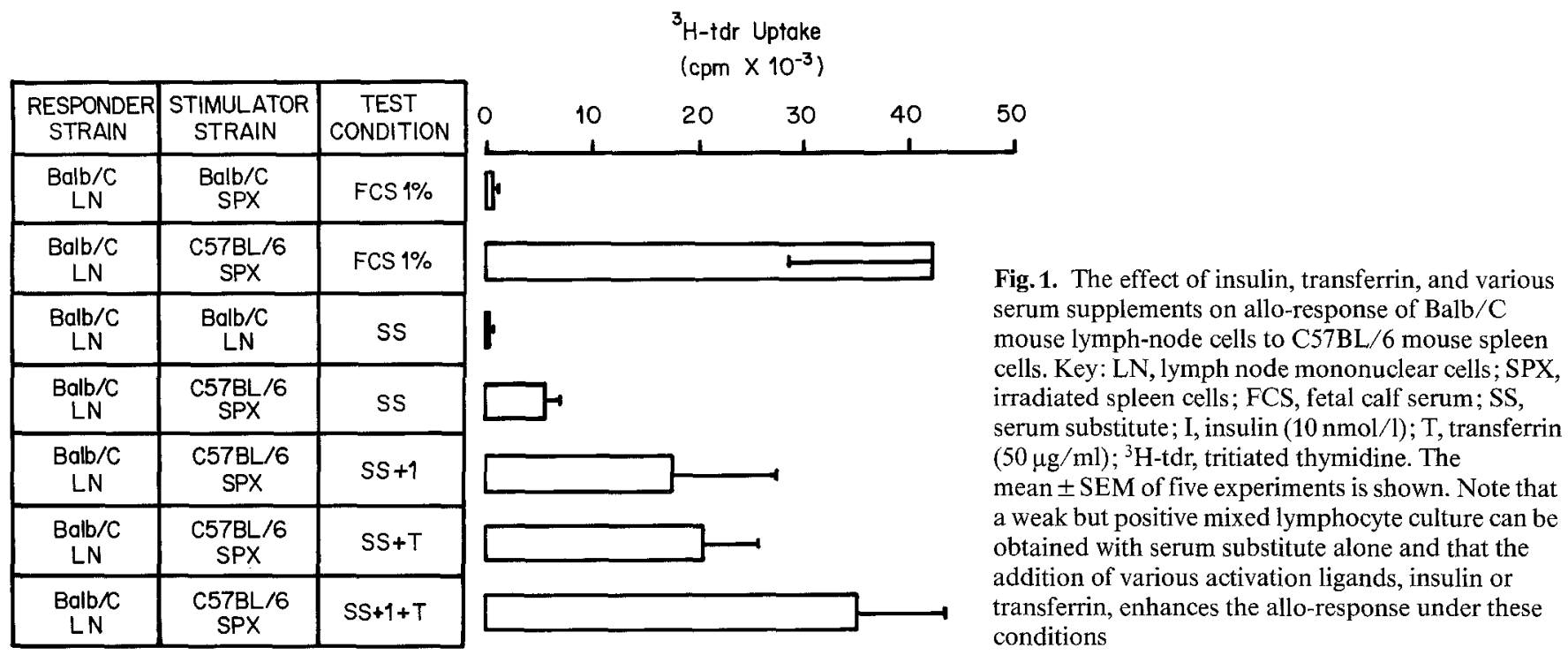

was insulin-depleted by passage over insulin-antibody affinity columns. Highly specific anti-insulin antibodies were coupled to $\mathrm{CnBr}$ activated Sepharose $4 \mathrm{~B}$ resin, washed thrice in $\mathrm{HCl}(1 \mathrm{mmol} / 1)$ in a coupling buffer of $1.0 \mathrm{~mol} \mathrm{NaHCO}_{3} / 0.5 \mathrm{~mol} \mathrm{NaCl}, \mathrm{pH} 8.3$. Ethanolamine blocked remaining active groups and then was washed away with successive washes of coupling buffer and $\mathrm{Na}$ acetate buffer $(0.1 \mathrm{~mol}, \mathrm{pH} 4$, with $0.5 \mathrm{~mol} / 1 \mathrm{NaCl})$. Gel volumes $(6 \mathrm{ml})$ were packed into sterile $12-\mathrm{ml}$ syringes, each fitted with a 16-gauge needle. Fetal calf serum was percolated slowly over the column. The effluent from the column contained no detectable insulin when assayed by Herbert et al.'s modification of the Yalow and Berson radioimmunoassay $[4,5]$.

\section{Artificial serum substitute}

To explore the role of residual growth factors in the insulin-depleted fetal calf serum, an artificial serum substitute was made similar to that described by Snow et al. [6]. Bacto-peptone $(5 \mathrm{~g})$ was mixed with $2.5 \mathrm{~g}$ of lactalbumin hydrolysate, $0.5 \mathrm{~g}$ yeastolate, and $0.5 \mathrm{~g}$ dextrose in distilled water under moderate heat. Aggregates were removed by centrifugation at $1400 \mathrm{~g}$ and autoclaved before use. In these mixed lymphocyte reactions, $1 \%$ fetal calf serum with and without insulin served as control, while mixed lymphocyte reactions were established with $1 \%$ serum substitute to which was added buffer, insulin $(10 \mathrm{nmol} / 1)$, transferrin $(50 \mu \mathrm{g} / \mathrm{ml})$, or both insulin and transferrin.

\section{Results}

\section{Insulin depletion and the mixed lymphocyte reaction}

In these studies we explored the impact of removal of insulin from fetal calf serum on the ability to generate an allo-response. Syngeneic cultures with Balb/C lymph node cells responding to Balb/C spleen cells irradiated in media containing $1 \%$ fetal calf serum incorporated $84 \pm 15 \mathrm{cpm}$ of ${ }^{3} \mathrm{H}$-thymidine after a $16-\mathrm{h}$ pulse. The allogeneic culture with $\mathrm{Balb} / \mathrm{C}$ responding to C57BL/ 6 cells in the complete fetal calf serum incorporated $22783 \pm 4934 \mathrm{cpm}$. The allo-response therefore gave a stimulation index of 271 -fold. The syngeneic cultures in the setting of insulin-depleted fetal calf serum incorporated $475 \pm 149 \mathrm{cpm}$, while a strongly positive mixed lymphocyte reaction was still the result of the allogeneic cultures even in the face of insulin depletion $(24915 \pm 242 \mathrm{cpm})$. One can conclude from these studies that insulin is not the sole factor in fetal calf serum which supports and maintains the active state of the allo-stimulated lymphocyte under these conditions; some other factor(s), capable of sustaining such a response in the absence of insulin, must also be present.

\section{Artificial serum substitute and the mixed lymphocyte reaction}

The results of five experiments are depicted in Figure 1. Syngeneic incorporation of ${ }^{3} \mathrm{H}$-thymidine was similar for cultures in all the test conditions, ranging from 487 to $653 \mathrm{cpm}$. The allogeneic culture performed in $1 \% \mathrm{fe}-$ tal calf serum with its normal concentration of insulin and transferrin incorporated $13964 \mathrm{cpm}$. The serum substitute permitted a much weaker but definitely positive mixed lymphocyte reaction $(5800 \mathrm{cpm}$, a stimulation index of 12.5). Addition of insulin alone in this experiment raised the DNA base incorporation to $8589 \mathrm{cpm}$. In the group taken as a whole, there was no significant difference between whole fetal calf serum and insulin $(10 \mathrm{nmol} / \mathrm{l})$. Transferrin in a dose known to stimulate maximally several aspects of immune function actually enhanced the mixed lymphocyte reaction response $(23128 \mathrm{cpm})$, while the insulin and transferrin combination gave no significant further enhancement $(25555 \mathrm{cpm})$. These studies reveal that one can establish a positive allo-response in a serum-substituted culture which provides an important model to test the role of the hormones and growth factors insulin and transferrin. Insulin alone restores the active state of the lymphocyte after allo-antigenic response. Transferrin alone can also support mixed lymphocyte reaction responses. 


\section{Discussion}

It is a clinical observation that diabetic patients may have an intrinsic defect in immunity against infection [7]. In particular, defects in T-lymphocyte function have been reported by some $[8,9]$ as part of the explanation for altered transplant and infection immunity. This study begins an exploration of the role of insulin in the maintenance of allo-responses by insulin-receptor-bearing lymphocytes.

Lymphocytes appreciate viruses in the context of HLA class II antigens, the same antigens being responsible for allo-stimulation in the mixed lymphocyte response. Thus the mixed lymphocyte reaction is a valid model with which to explore the impact of insulin as an immuno-modulating molecule on transplant and infection immunity.

The insulin-dependent diabetic patient has deficient insulin concentrations, constantly at diagnosis and for much of the day under conventional pulse insulin replacement therapy. Thus if insulin subserves the crucial role in maintaining the active state of lymphocytes after an allo-response, one might expect to identify the insulin-deficient state as an important feature in the altered immunity of diabetes mellitus.

In these experiments we have shown that serum depleted of all its insulin can still support the mixed lymphocyte reaction in vitro. It contains a factor(s) which by itself either substitutes for insulin or is of primary importance in permitting the allo-stimulation provided by class II antigen differences present in the murine mixed lymphocyte reaction used in these studies. A likely candidate for this factor is transferrin. To analyse the respective roles for insulin and transferrin, we excluded background effects due to hormones, neurotransmitters or growth factors by employing the artificial serum substitute described by Snow et al. [6] to support lectin responses in murine cultures. The serum substitute medium was capable of supporting a weak but definite mixed lymphocyte response. In these studies we showed that addition of insulin $(10 \mathrm{nmol} / \mathrm{l})$ itself restored allo-response to normal. One can conclude that insulin alone is fully capable of supporting allo-stimulatory responses of receptor-bearing lymphocytes. However, transferrin at doses known to be maximal for other assays of immune function was fully capable of sustain- ing the mixed lymphocyte reaction. There was no major additive effect of the two growth factors. Thus fetal calf serum depleted of insulin may support the mixed lymphocyte reaction by virtue of its transferrin content.

Assuming that these findings in cultured murine lymphocytes apply also in man, it follows that the insulin-dependent diabetic patient does not exhibit impaired allogeneic responsiveness as a result of insulin deficiency. One can surmise that residual transferrin, as well as other immunoregulatory hormones, might fully substitute for the absent insulin when full allo-antigenic stimulation is provided. Insulin may actually have a fail-safe role in maintaining the active status of lymphocytes if less than maximal antigenic signals are provided. This potential role for insulin is under study.

Acknowledgement. This paper was supported by NIH grant AM 22150 .

\section{References}

1. Helderman JH, Strom TB (1977) The emergence of insulin receptors upon alloimmune cells in the rat. J Clin Invest 59: 338-344

2. Helderman JH (1981) The role of insulin in the intermediary metabolism of the activated thymic derived lymphocyte. J Clin Invest 67 : $1636-1642$

3. Kumagai J-I, Akiyama H, Iwashita S, Iida H, Yahara I (1981) In vitro regeneration of resting lymphocytes from stimulated lymphocytes and its inhibition by insulin. J Immunol 126: 1249-1254

4. Herbert V, Lau KS, Gottlieb CW, Bleicher SJ (1965) Coated charcoal immunoassay of insulin. J Clin Endocrinol Metab 25: 1375-1385

5. Yalow RS, Berson SA (1960) Immunoassay of endogenous plasma insulin in man. J Clin Invest 39: 1157-1175

6. Snow EC, Feldbush TL, Oaks JA (1980) The role of insulin in the response of murine $T$-lymphocytes to mitogenic stimulation in vitro. J Immunol 124: 739-744

7. Marble A, White HJ, Fernald AT (1938) The nature of the lowered resistance to infection in diabetes mellitus. J Clin Invest 17: 423-430

8. Plouffe JF, Silva J, Fekety R (1978) Cell-mediated immunity in diabetes mellitus. Infect Immunol 21: 425-429

9. Delespesse G, Duchateau J, Bastenie PA (1974) Cell mediated immunity in diabetes mellitus. Clin Exp Immunol 18: 461-467

Dr. J. Harold Helderman

University of Texas Health Science Center at Dallas

5323 Harry Hines Boulevard

Dallas, TX 75235

USA 